\title{
A Reflection of Comprehensive Evaluation Matriculation in Universities from the Perspective of Educational Equality
}

\author{
Chun-lan GUAN ${ }^{1, a,{ }^{*}}$ \\ ${ }^{1}$ School of Electrical Power, South China University of Technology, Guangzhou \\ 510640, China \\ achlguan@scut.edu.cn \\ ${ }^{*}$ Corresponding author
}

Keywords: Comprehensive evaluated matriculation, Educational equality, University matriculation.

\begin{abstract}
In recent years, China has paid more and more attention in multiple university matriculation institution, which encourages the appearance of Comprehensive Evaluated Matriculation. Meanwhile, educational equality has gotten increasing attention from Chinese people. On this premise, discuss the educational equality effect of comprehensive evaluated matriculation is meaningful practically. This paper introduces the development history of the university matriculation institution in China. Then, the equality problems of matriculation based on college entrance examination and Autonomous Matriculation are analyzed. On this basis, the effect of comprehensive evaluated matriculation on educational equality is shown in this paper. Finally, this paper comes up with some suggestions which could increase the educational equality.
\end{abstract}

\section{Introduction}

Equality is the equal relation between everyone, which means taking the single uniform for generality while for the individuality, we should treat it respectively. Educational equality is the extension and reflection of social justice value theory in the educational field. And educational equality is the fundamental claim that people call for in the progress of developing harmonious society. As higher education is a rare educational resource, the matriculation institution of universities has attracted broad attention nationwide. Since 2007, to establish a better university matriculation institution, many universities in China began to carry out the pilot of comprehensive evaluated matriculation, which is new in China. Analyzing the effect that brought by comprehensive evaluated matriculation on educational equality is of great importance in this situation.

This paper introduces the developing progress of university matriculation institution in China. Then based on analysis of equal problems that caused by College Entrance Examination Matriculation and Autonomous Matriculation, the effect on educational equality that caused by comprehensive evaluated matriculation is discussed. Last but not least, this paper proposed some advice aiming at the shortage of comprehensive evaluated matriculation. 


\section{The Development Process of University Matriculation Institution in China}

In 1952, the college entrance examination is carried out in China. Since then, the college entrance examination scores has become the main assessment index in university matriculation [1]. The enrollment of universities and the job of graduated college students were all distributed by government before, but nowadays, it has changed to students choose the universities and the jobs themselves. In recent 10 years, there are more than 5 million students that get the opportunity of going to universities through college entrance examination every year [2]. However, college entrance examination scores are still the only standard that deciding whether the student could be enrolled by the university or not.

In 2003, China begins to implement the experimental reforms of Autonomous Matriculation, which is called the "icebreaker" in the field of university matriculation revolution in China. In the revolution experimental places, the scores of written examination and interview are the main reference measures, and consider the grade in middle school, daily performance, evaluation of other people and growth record in the same time [3]. In recent years, there are more than 10 thousand students that take part in the Autonomous Matriculation.

Since 2007, the experimental revolution of Comprehensive Evaluated Matriculation is coming up in many places [4]. In 2014, Chinese government issues the < The implementation of the state council on deepening the reform of examination recruitment system> (simplify as <the implementation> in rest of the paper) [5], which proposes the requirement of "carrying out multiple matriculation institution that based on the scores of college entrance examination and academic tests in high school, and consulted the multiple quality evaluation". Before 2016, there are 88 universities that have taken part in the experimental revolution of Comprehensive Evaluated Matriculation [4]. Predictably, there will be more and more universities that taking the Comprehensive Evaluated Matriculation when the institution is getting more mature.

\section{The Equality Problems Existing in College Entrance Examination Matriculation and Autonomous Matriculation}

\section{Equality Problems Existing in College Entrance Examination Matriculation}

The procedure of College Entrance Examination Matriculation is as follows. First, high school students take part in the college entrance examination and hand in their college aspiration. Then, the university will enroll the students by the rank of scores. However, the decision that only considers the scores can't evaluate the comprehensive qualities of students completely, which will bring following equality problems.

Firstly, the comprehensive ability of different kinds of students can't be evaluated completely if only considers the scores. In the background of unified examination, students are unable to reveal their advantages adequately. Especially when the advantages of the student are not included in the college entrance examination subjects, the ability of the student is still defined by the fields that he is not good at, which have great negative effect on students when he choosing the universities, and many talents who only good at some fields are missed.

Furthermore, only basing on the examination scores can't satisfy the needs of universities that have different characteristics or in different levels. With the strict stipulation of recruiting by the rank of scores, university can't put forward some 
specific requirement according to their disciplines status, which makes it harder for them to develop their advantage discipline and enhance competitiveness.

Last but not least, "parallel application" will worsen the development unbalance of different universities. Parallel application takes the scores in the first place, and many students can be enrolled in the first application. But paying too much attention in the score equality will lead to the simplification of source of university students and flattening of scores, which makes it impossible for universities to get high scores students accidentally. The gap of different universities will be larger and the unbalance of different universities will be worsening.

\section{Equality Problems Existing in Autonomous Matriculation}

Autonomous Matriculation increases the independence of universities in matriculation. Universities can recruit some students according to their needs, while students who have talent in some fields can get a better education opportunity by Autonomous Matriculation. However, although Autonomous Matriculation fixes some problems that caused by College Entrance Examination Matriculation and considers the comprehensive quality of students, there are still many equality problems existing in Autonomous Matriculation, which is shown as follows.

First problem is qualification examination of students. There are no strict stipulations in qualification examination. Although the application requirements of many universities are similar, such as obtaining some national or provincial awards, ranking the top grade in his school, having special talents, etc., there are no specific quantification indexes of the requirements. And the priority of the requirements is not decided either, which leaves great equality hidden trouble in practice. Besides, the program of qualification examination is not precise, and the authenticity of different certificates is hard to distinguish since universities don't have enough resources to check it one by one. So there might be some students, who should not have the qualification, get the opportunity of Autonomous Matriculation by cheating. All of these will make the operation of Autonomous Matriculation lose its justice.

Secondly, there are some problems about the program of matriculation and examination. In the matriculation program of Autonomous Matriculation, the Ministry of Education only sets some key steps. It extends the independence of universities, but it also makes there is no specific basis for Autonomous Matriculation programs, which breeds corruption [6]. Meanwhile, attach great importance to students taking part in the writing exams and interviews will increase the cost of Autonomous Matriculation greatly. It becomes the obstacle to develop and popularize Autonomous Matriculation, which lead to the equality problems.

In addition, geography is unfair in Autonomous Matriculation. Generally, there are writing exams and interviews in Autonomous Matriculation. Writing exams usually concern about hot spots of society, which investigate what students learn about the hot spot of society and their innovation thoughts. Interviews often inspect the adaptability to changes and comprehensive qualities of students. Apparently, rural students are in inferior position no matter in writing exams or interviews [7]. However, the so-call inferiority is not the definite index that representing the creativity and potential of students. Besides, Autonomous Matriculation tends to give more opportunities to the developed places and the key schools, which make the educational unfairness of different places is worse.

Moreover, the supervision system is incomplete. For Autonomous Matriculation, the interest bodies consist of students, high schools, universities and education 
administrative departments. But there is no powerful equilibrium mechanism among these interest bodies. Furthermore, to consummate the equilibrium mechanism, punishment to those breaking the laws is necessary. But most of the laws just stipulate Autonomous Matriculation simply, and the right of students during Autonomous Matriculation is not clear, which have few binding to the interest bodies. So the equality problems arise endlessly in this situation.

\section{The Effect on Educational Equality Caused by Comprehensive Evaluation Matriculation}

Comprehensive Evaluation Matriculation is carried out by some universities which have joined in the revolution experimental spots. It considers the college entrance examination scores, academic texts scores, the assessment conclusion by universities, the comprehensive quality evaluation by high schools and the development demands of universities comprehensively. Students who meet the requirement of college entrance examination scores can choose to take part in the comprehensive evaluation matriculation. Universities will evaluate them comprehensively and recruit the elitists ${ }^{[8]}$. In this section, this paper will analyze the <the Implementation> and enrollment guides of different universities, and scan the effect on educational equality caused by comprehensive evaluation matriculation.

\section{Qualification Examination of Students}

According to the concept of comprehensive evaluation matriculation, there is strict request for the college entrance examination scores, and the scores of college entrance examination and academic texts have great impact on the result of the comprehensive evaluation matriculation. Setting the scores of unified exams as precondition makes for students getting the opportunities equally, which reduce the possibility of corruption and the influence of people, guaranteeing the right to education of every student.

Meanwhile, <the Implementation> presents the requirements of "making the program precise, enhancing the supervision system, revealing the message and guaranteeing the authenticity of students' application material" to comprehensive quality evaluation, which makes sure that high schools should take the responsibility of supervising the authenticity of materials. It reduces the possibility of cheating, which lessens the problems of educational equality.

\section{Content and Form of the Exam}

The program of Comprehensive Evaluation Matriculation is during the time that after the college entrance examination scores released and before the application enrollment, which helps to guarantee the equality of Comprehensive Evaluation Matriculation and without affecting the enrollment of college entrance examination. In the same time, the Comprehensive Evaluation Matriculation is based on the scores of college entrance examination and academic texts and considering the development needs of universities. For rural students, it reduces the inequality between urban and rural places when considering the results of unified exams, because the scores of those exams are something they can improve easier. In addition, emphasizing the advantage disciplines helps students give full play to superior subjects. No matter rural students or urban students, they could be discovered by experienced teachers and gain the enrollment opportunity. 


\section{Enrollment Areas}

Aiming at solving the inequality between different places and different high schools, $<$ the implementation> presents the requirements of "boosting the matriculation ratio in middle and western areas" and "increasing the number of rural students recruited by key universities", which guide the development of comprehensive evaluation matriculation. But the practical execution of universities still needs to be verified by time.

\section{Supervision System}

In past years, the platform of matriculation was developed by the union or the university itself, so the application program and public information are different between different places. The forth section of <the Implementation> about supervision system revolution proposed the requirement that universities should release 10 kinds of information about the matriculation. On this background, universities that carry out the Comprehensive Evaluation Matriculation should obey this requirement so that the difficulty of the universities is lightened when doing the matriculation. And the Comprehensive Evaluation Matriculation also enjoys a better supervision system.

$<$ The implementation $>$ also mentions that "those who breaks the laws should be punish seriously, enhance the supervision during the matriculation and the parties should take their own responsibility", which create strong restraint between interest bodies and reduce the incident that abusing the power. <The implementation> encourages universities using third-party supervision as well.

From the analysis above, <the implementation> could help to public the matriculation information, complete the supervision system and create the restraint. The Comprehensive Evaluation Matriculation that generating in this background has taken the stipulations of <the implementation>, which will bring positive impact on educational equality and help to realize the goal of educational justice.

\section{Some Advice about Improving the Equality of Comprehensive Evaluation Matriculation}

By the previous section, we can know that there is significant meaning of Comprehensive Evaluation Matriculation in realizing educational equality, which have improvements about qualification examination, content and form of the exam, enrollment areas and supervision system. But there are still some problems that exist in the Comprehensive Evaluation Matriculation since it is in the experimental stage. For example, Comprehensive Evaluation Matriculation is still carried out by a few key universities, which doesn't solve the problem of inequality of different universities totally. And although there is guidance about exam costs and enrollment areas, the practical situation is uncertain now.

To solve the problems that mentioned above and push Comprehensive Evaluation Matriculation being more mature and complete, this paper proposed some advice as follows:

Firstly, the standard and program of Comprehensive Evaluation Matriculation should be considered from the perspective of students and based on the goal of guaranteeing the educational equality. It should reflect the ability and potential of students objectively and should be carried out easily.

Secondly, complete the supervision system and the balance mechanism between different interest bodies. Make sure the form of punishment by laws and increase 
punishment to those breaking laws seriously, providing educational equality legal protection.

Last but not least, establish specific training methods for students who recruit by comprehensive evaluation matriculation, and focus on the development of the students, making sure that the advantages of the students are developed adequately.

\section{Conclusions}

Comprehensive Evaluation Matriculation is a significant measure in China, which experiments multiple matriculation institution, revolute the present educational institution and improves the educational equality. It integrates the advantages of College Entrance Examination Matriculation and Autonomous Matriculation, which gives more opportunities for talented students to gain better education. It also fixes some problems that existing in College Entrance Examination Matriculation and Autonomous Matriculation, bring positive impact on realizing educational equality. This paper begins with the history of matriculation in China, and analyzed the equality problems of College Entrance Examination Matriculation and Autonomous Matriculation. On this basis, this paper shows the effect of Comprehensive Evaluation Matriculation on educational equality, drawing the conclusion that Comprehensive Evaluation Matriculation could improve the educational equality. Meanwhile, it also proposes some advice about the development of comprehensive evaluation matriculation, which could be referred by relevant workers.

\section{References}

[1] M.Z. Li, The revolution and changes of college entrance examination institution: effect, difficulty and tendency (In Chinese), Journal of Hubei University (Philosophy and Social Science), 2(2015):138-143.

[2] Information on http://learning.sohu.com/20151130/n428864496.shtml

[3] Q. Lin, Research on the History, Status and Development Trend of the Autonomous Universities Enrollment System in China (In Chinese), Jiangxi Normal University, 2012.

[4] X.C. Bian, the Development Course, Mode and Value Orientation of Comprehensive Evaluation Reform in University Admission: Comparison with Independent Recruitment (In Chinese), Research on Reform of College Entrance Examination, 8(2016).

[5] Information on http://www.gov.cn/zhengce/content/2014-09/04/content_9065.htm

[6] W.P. Zhang, J. J. Gao, the Equality Explanation of Autonomous Matriculation: Meaning, Problem and Development (In Chinese), Modern Education and Management, 7(2011):12-17.

[7] S. S. Wang, Research on the Effect of Autonomous Matriculation on Rural Students from the Perspective of Educational Equality (In Chinese), Instruction of Education and Science, 1 (2015):11-12.

[8] C.X. Lv, C.Y. Le, analysis about trinity comprehensive evaluation matriculation revolution in universities (In Chinese), educational research, 1(2014):98-104. 